\title{
Variations in anxiolytic and hypnotic prescribing by GPs: a cross-sectional analysis using data from the UK Quality and Outcomes Framework
}

\author{
Zoi Tsimtsiou, Mark Ashworth, and Roger Jones
}

\begin{abstract}
Background

Wide variations in anxiolytic and hypnotic prescribing by GPs in England have been described, but are largely unexplained.

Aim

To examine the relationships between the volume of anxiolytics and hypnotics prescribed by GPs and their practice characteristics, population demography, and performance indicators.

Design of study

Cross-sectional study.

Setting

All general practices in England.

Methods

A dataset was constructed for 8469 (98.8\%) general practices including: standardised prescribing volume data for anxiolytics and hypnotics (average daily quantities per 1000 STAR-PUs [Specific Therapeutic group Age-sex weightings Related Prescribing Units]), practice descriptors, Index of Multiple Deprivation 2004, ethnicity data (2001 UK Census), and Quality and Outcomes Framework (QOF) data.
\end{abstract}

Results

The standardised volume of anxiolytics and hypnotics prescribed varied eightfold between practices on the 5th and 95th centiles. A regression model was constructed which explained $20.5 \%$ of the variation. Higher prescribing practices were located in more deprived areas (standardised $\beta$ 0.31), but also in areas with a lower proportion of ethnic minorities (black or black British $=-0.22$; Asian or Asian British $=-0.12$ ). Higher volumes were also prescribed by practices with lower QOF scores ('Clinical Care' domain $=-0.12$; 'Organisational' domain $=-0.08$ ). Other significant but weaker predictors were: lower proportions of female GPs, higher recorded prevalence of serious mental illness and non-training status. The proportion of GPs trained outside UK was not a predictor.

\section{Conclusion}

Demographic factors were more powerful determinants of prescribing than characteristics of the practice itself. Nevertheless, the findings provide some support for the notion that high prescribing practices were less well developed, in that their QOF scores were lower and they were less likely to be training practices.

Keywords

anxiolytics; general practice; hypnotics; prescribing.

\section{INTRODUCTION}

There has been concern for many years about the high volume of anxiolytic and hypnotic prescribing by GPs with the implication that some prescribing might be inappropriate and contribute to the problem of physical and psychological dependence or may be responsible for masking underlying depression. ${ }^{1,2}$ This concern has to be set against a background of declining prescribing volumes of anxiolytics and hypnotics in England over recent years (Figure 1), reflecting increased awareness of concerns about long-term prescribing of these medications. Practices vary considerably in the number of anxiolytics and hypnotics that they prescribe, but this variation has received little research attention. ${ }^{3,4}$

Previous studies on predictors of anxiolytic and hypnotic prescribing, mainly at regional level, have demonstrated that some of the variation can be explained, but the determinants appeared to be weak and often inconsistent..$^{3-5}$ The majority of the variation in prescribing patterns is still poorly understood. Conflicting findings have been reported about the importance of the size and type of the

$Z$ Tsimtsiou, MD, MSc, PhD, honorary research fellow; M Ashworth, DM, FRCGP, clinical senior lecturer; $\boldsymbol{R}$ Jones, $D M$, FRCGP, Wolfson professor of general practice,

Department of General Practice and Primary Care, King's College London School of Medicine at Guy's, King's College and St Thomas' Hospitals, London.

Address for correspondence

Mark Ashworth, King's College London School of Medicine at Guy's, King's College and St Thomas' Hospitals, Department of General Practice and Primary Care, 5 Lambeth Walk, King's College London, London, SE11 6SP. E-mail: mark.ashworth@kcl.ac.uk

Submitted: 14 August 2008; Editor's response: 13 November 2008; final acceptance: 15 January 2009. (O)British Journal of General Practice.

This is the full-length article of an abridged version published in print. Cite this article as: Br J Gen Pract 2009; DOI: 10.3399/bjgp09X420923. 
practice and the age and sex of the GPs. ${ }^{3,6-9}$ A recent study in east London suggested that prescribing volumes of anxiolytics and hypnotics were similar between South Asian and UK trained GPs, although UK trained GPs prescribed fewer antidepressants. ${ }^{10}$ South Asian trained GPs were found to prescribe more medication than UK trained GPs in a national study exploring prescribing in all English regions (the difference applied to frequency but not to cost). ${ }^{11}$ In the latter study, deprivation was the major determinant of variation in overall prescribing, ${ }^{11}$ while Pharoah and Melzer have found that deprivation did not influence anxiolytic and hypnotic prescribing significantly in practices in Cambridge and Huntingdon and neither did a number of variables relating to the structure and organization of the practice. ${ }^{4}$ This lack of association with social deprivation may have been a reflection of the relatively narrow social gradient in this part of the country. Lower prescribing rates have been reported in Asian communities in east London and in black neighbourhood residents in a number of US studies, although other ethnic groups have not been previously studied in UK.,12-14 Other factors associated with high prescription rates include being female, ${ }^{4,12,14,15}$ older, ${ }^{3,4,9,12,13,15}$ lower educational status, ${ }^{13}$ marital status (separated or divorced) $){ }^{13}$ proportion of temporary residents, ${ }^{4}$ and the concurrence of chronic somatic and serious mental illnesses. ${ }^{9,13-16}$

The new contract for GPs in the UK has provided a wealth of new descriptive and epidemiological data about the performance of general practice (Quality and Outcomes Framework [QOF] data), ${ }^{17}$ and the opportunity for studies at a national level. Established in 2004, the QOF gives financial incentives to GPs for achieving certain performance targets in four main domains: Clinical Care, Organisational, Patient Experience, and Additional Services (such as cervical

\section{How this fits in}

Small scale studies have produced conflicting findings about the importance of the demography of the practice population and the characteristics of the GPs and their practices in explaining the wide variation of anxiolytics and hypnotics prescribed in primary care settings in England. On the basis of a national study, this study confirms the importance of social deprivation as a determinant of high levels of anxiolytic and hypnotic prescribing, although GPs working in areas with a higher proportion of ethnic minorities prescribe fewer anxiolytics and hypnotics. Practices with higher QOF scores and training practices prescribe fewer anxiolytics and hypnotics. The proportion of GPs qualified outside UK within practices is not a predictor of anxiolytic and hypnotic prescribing.

smears or maternity services). ${ }^{18}$

The identification of parameters predicting the volume of anxiolytic and hypnotic prescribing throughout general practices in England is expected to provide an insight into the reasons why practices vary widely in the amount of these drugs which they prescribe. Prescribing of these drugs is often used as a proxy indicator of prescribing quality, and the point of this study was to explore whether this is supported by evidence of association with other indicators that describe aspects of quality. ${ }^{19}$ Social deprivation has been linked with high volumes of anxiolytic and hypnotic prescribing. ${ }^{11}$ The aim of the study was to explore the predictors of anxiolytic and hypnotic prescribing in general practice in England and to determine the relative influences of the local demography, characteristics of the GPs and their practices, and the achievement of performance indicators included in the QOF data set.

\section{METHOD}

\section{QOF data}

QOF data for all general practices in England $(n=$

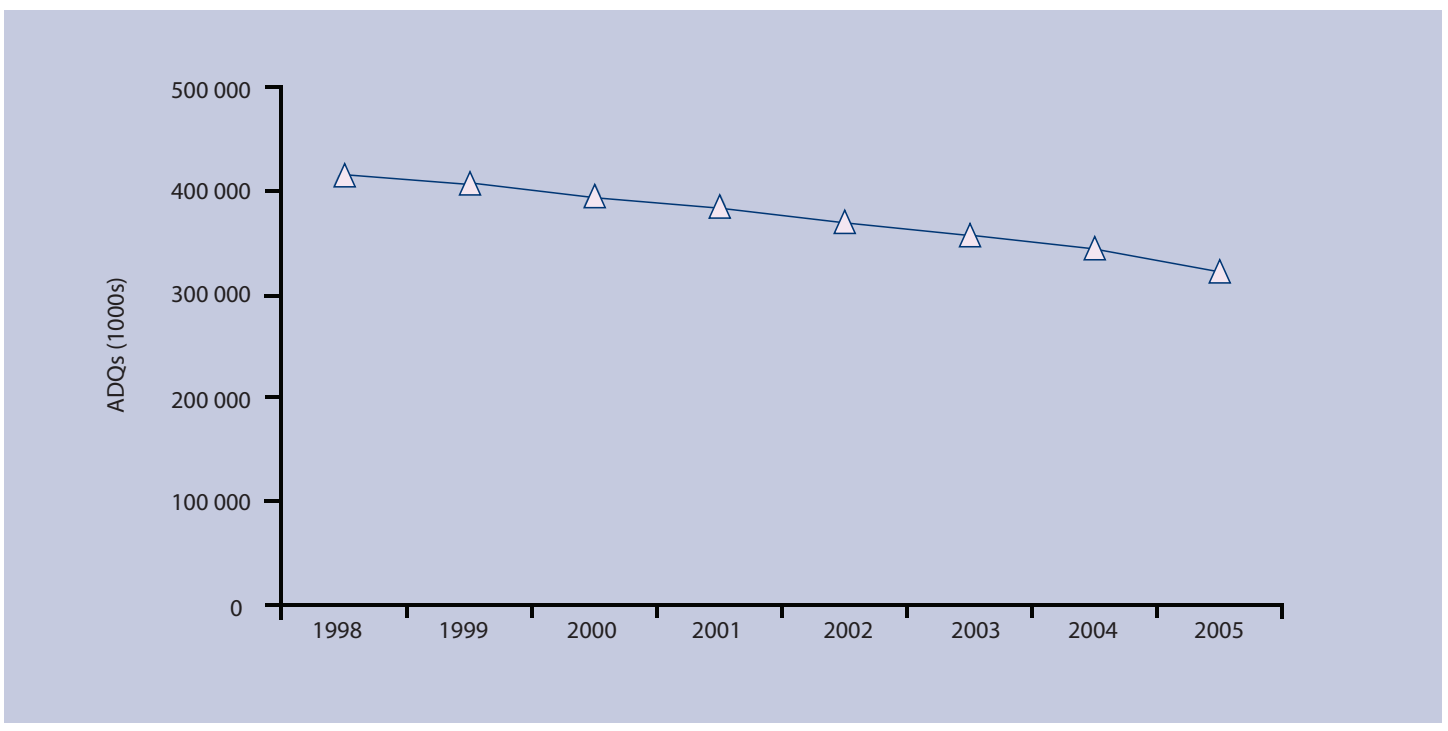

Figure 1. Total number of average daily quantities (in 1000s) according to all anxiolytic and hypnotic prescriptions dispensed in the community in England from 1998 to 2005. Barbiturates are excluded. Source: Department of Health, Statistics Division 1E, Prescription Cost Analysis System). 
8576) for the years 2004-2005 were obtained from The Information Centre for Health and Social Care, Leeds. QOF data were aggregated at domain level (achievement of the overall Clinical Care, Organisational, Patient Experience, and Additional Service domains). ${ }^{20}$ The dataset also incorporated the practice-based prevalence values for 'Serious Mental Illnesses', one of the 11 chronic conditions included in QOF, which was loosely defined in the study year as, 'any patient with serious impairment as a result of a mental illness'.

\section{Practice characteristics}

A detailed summary of practice characteristics was obtained from the Primary Care Research and Development Centre, University of Manchester. Data included: list size, training practice status, age/sex breakdown of registered population, as well as the number of full-time equivalent GPs. ${ }^{21}$

\section{Anxiolytic and hypnotic prescribing data}

Prescribing data were collected from April 2004 to March 2005 from national prescribing analysis and cost tabulation data, and were provided by the Prescription Pricing Division in Newcastle..$^{22}$ Data were used relating to 'anxiolytics and hypnotics', the term used to describe drugs included in Chapter 4.1 of the British National Formulary (BNF; excluding barbiturates). Similar data were obtained describing the volume of antidepressant and major tranquilliser prescribing (BNF chapters 4.2 and 4.3 respectively).

The volume of prescribing was standardised using average daily quantities (ADQs), a measure which makes allowance for differences in the duration of each prescription. ${ }^{23}$ The total number of patients registered at each practice and their age/sex profile were standardised using Specific Therapeutic group Age-sex weightings-Related Prescribing Units (STARPUs). ${ }^{24}$ STAR-PUs act as a standardised measure of all patients registered at each practice, weighted according to national prescribing patterns. STAR-PU ratings exist for several categories of medication and those used in the current study were specific to anxiolytics and hypnotics (as contained in Chapter 4.1 of the BNF). Anxiolytic and hypnotic prescribing was expressed as the standardised volume prescribed for the standardised registered population at the practice (ADQs per 1000 STAR-PUs).

\section{Census-based variables}

Data from the 2001 UK National Census were obtained and linked to practice data using the Super Output Area (SOA) for each practice. ${ }^{25}$ SOAs are geographical, 'socially homogenous' areas containing an average population of about 1500 people. SOAs form the basis for calculating the Index of Multiple Deprivation (IMD) 2004..$^{25}$ IMD data are only available at practice rather than at patient level in England. Census-derived ethnicity figures were obtained, again based on SOAs linked to general practice postcodes, and aggregated at the level of the five main ethnic groupings: white or white British, black or black British, Asian or Asian British, mixed, and Chinese or other (data provided by the Informatics Collaboratory of the Social Sciences, University of Sheffield).

\section{Statistical analysis}

A dataset was constructed containing data from all 8576 practices in England, their QOF data, practice and census-based variables and prescribing data. Sixty-one $(0.7 \%)$ practices were excluded from the analysis because they were no longer independent at the end of the study year or had a list size of under 750 patients or under 500 per full-time GP; these were excluded as it was considered likely that they were either new practices or practices about to close. Postcode and SOA code anomalies meant that QOF data could only be matched to IMD data for 8480 (98.8\%) practices, while anxiolytic and hypnotic prescribing data were available for 8509 $(99.2 \%)$ practices. A further twenty practices from the final analysis were omitted because they did not prescribe any anxiolytics and hypnotics during the year of study. It was considered likely that this was an artifact and a zero value would have had an undue effect on the final regression model. The equivalent number of practices with extreme high values $(>7$ interquartiles beyond the 75th percentile) were also omitted as these too were likely to be highly atypical practices, probably specialising treatment of benzodiazepine dependence. The final dataset consisted of 8469 (98.8\%) practices.

Data were analysed using the SPSS (version 15.0). Given the size of the database containing information on more than 8000 practices, the central limit theorem ensures that parametric tests are valid. Regression models were used to explore the univariate associations between the volume of anxiolytics and hypnotics, and the QOF-, practice-, and census-derived predictor variables. All variables with significant univariate association with the volume of anxiolytics and hypnotics were then included in a multivariate analysis using multiple linear regression based on the forward stepwise method.

\section{RESULTS}

The standardised volume of anxiolytic and hypnotic prescribing varied widely between practices (Figure 2): the median volume was 9862 ADQs per 1000 STAR-PUs; interquartile range: 6776 to 14120 ; 5th 
and 95th centiles: 3093 to 24967 .

The characteristics of the GPs and their practices, the demography of the practice population, and the QOF indicators included in this study are summarised in Table 1. Univariate associations between the standardised values for anxiolytics and hypnotics and the predictor variables included are summarised in Table 2.

The standardised volume of anxiolytic and hypnotic prescribing was positively correlated with both major tranquilliser and antidepressant prescribing volumes (Pearson's $r=0.31$ and 0.37 respectively).

\section{Multivariate analysis}

A parsimonious regression model was constructed. Ten variables explained $20.5 \%$ of the variation in anxiolytic and hypnotic prescribing volume (Table 3). The adjusted regression coefficients demonstrate the effect of each variable after adjustment for confounding. After adjustment, the predictive power of four variables increased: the IMD score, the proportion of black or black British, and Asian or Asian British, and the Clinical Care domain score; these variables accounted for $17.7 \%$ of the variation.

\section{DISCUSSION}

\section{Summary of main findings}

The findings have demonstrated large variations in anxiolytic and hypnotic prescribing between general practices in England. The model that has emerged indicates that social deprivation is the major determinant of prescribing volume with higher

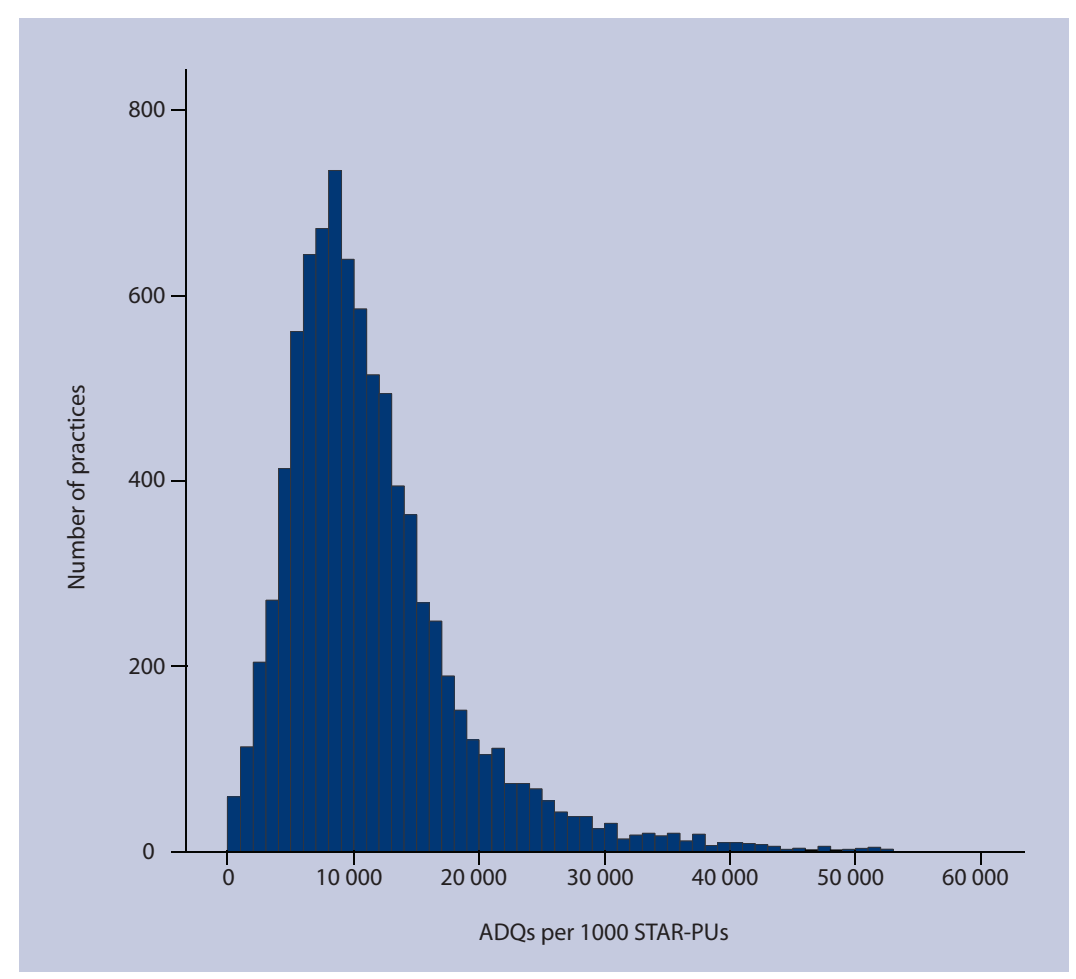

prescribing levels in more deprived areas. Conversely, practices based in areas with higher proportions of any ethnic minority and particularly black or black British people, prescribed fewer anxiolytics and hypnotics.

Certain practice attributes which could be considered as 'quality indicators' were associated with lower levels of prescribing, such as scoring histograms for the volume of anxiolytics and hypnotics prescribed (in average daily quantities per 1000 STARPUs [Specific Therapeutic group Age-sex weightings Related Prescribing Units]) in 8469 general practices in England.
Figure 2. Frequency

Table 1. Summary of the independent study variables.

\begin{tabular}{|c|c|}
\hline Index of Multiple Deprivation score, mean (SD), range & 25.88 (17.0), 0.74-84.7 \\
\hline Clinical Care domain total points achieved, mean (SD), range & 508.9 (60.3), 0-550 \\
\hline Organisational domain total points achieved, mean (SD), range & $161(27.7), 0-184$ \\
\hline Patient Experience domain total points achieved, mean (SD), range & 93.5 (16.6), 0-100 \\
\hline Additional Services domain total points achieved, mean (SD), range & $34.3(4.1), 0-36$ \\
\hline Group practice, \% & 74 \\
\hline Training practice, \% & 27 \\
\hline List size per full-time equivalent GP & $2199(755)$ \\
\hline Serious mental illness unadjusted prevalence, mean (SD) \% & $0.6(0.5)$ \\
\hline Proportion of population from an Asian or Asian British ethnic group, mean (SD) \% & $6.9(14.3)$ \\
\hline Proportion of population from a black or black British ethnic group, mean (SD) \% & $3.2(6.7)$ \\
\hline Proportion of population from a Chinese group or other ethnic group, mean (SD) \% & $1.1(1.6)$ \\
\hline Proportion of mixed population, mean (SD) \% & $1.5(1.5)$ \\
\hline Proportion of female GPs, mean (SD) \% & $32.3(28.5)$ \\
\hline Proportion of GPs $>65$ years old, mean (SD) \% & $4.6(18.1)$ \\
\hline Proportion of GPs trained in South Asia, mean (SD) \% & $22.9(37.0)$ \\
\hline Proportion of GPs trained in Europe (excluding UK), mean (SD) \% & $5.1(14.2)$ \\
\hline Proportion of GPs trained in Africa, mean (SD) \% & $3.2(12.7)$ \\
\hline
\end{tabular}


Table 2. Statistically significant univariate associations between anxiolytic and hypnotic prescribing volume and predictor variables.

\begin{tabular}{|c|c|c|c|}
\hline Variable & $\begin{array}{l}\mathrm{R}^{2} \text { (variation explained } \\
\text { by each variable [\%)] }\end{array}$ & $\begin{array}{c}\text { Unadjusted regression } \\
\text { coefficient, B }\end{array}$ & $95 \% \mathrm{Cl}$ \\
\hline Index of Multiple Deprivation score & 6.3 & 102.2 & 93.8 to 110.6 \\
\hline Proportion of population from a black or black British ethnic group & 3.4 & -190.2 & -211.7 to -168.6 \\
\hline Organisational domain total points achieved & 2.9 & -43.1 & -48.4 to -37.8 \\
\hline Proportion of female GPs & 2.5 & -3830.5 & -4346.2 to 3314.8 \\
\hline Clinical Care domain total points achieved & 2.3 & -18.1 & -20.6 to -15.6 \\
\hline Proportion of population from a Chinese or other ethnic group & 2.3 & -657.0 & -747.9 to -566.0 \\
\hline Proportion of mixed population & 1.7 & -619.0 & -719.2 to -518.9 \\
\hline Training practice & 1.6 & -1940.7 & -2271.3 to -1610.1 \\
\hline Patient Experience domain total points achieved & 1.1 & -43.7 & -52.6 to -34.7 \\
\hline Group practice & 0.9 & -1525.5 & -1863.4 to -1187.6 \\
\hline Additional Services domain total points achieved & 0.6 & -133.0 & -169.3 to -96.6 \\
\hline Proportion of population from an Asian or Asian British ethnic group & 0.5 & -33.0 & -43.3 to -22.7 \\
\hline Proportion of GPs trained in South Asia & 0.5 & 1347.5 & 945.5 to -1749.6 \\
\hline Proportion of GPs $>65$ years old & 0.3 & 2139.8 & 1316.5 to -2963.1 \\
\hline Proportion of GPs trained In Europe (excluding UK) & 0.2 & 2285.2 & 1234.1 to -3336.2 \\
\hline
\end{tabular}

more highly on chronic Clinical Care and Organisational QOF domains, or being a training practice. GPs who prescribed fewer anxiolytics and hypnotics were more likely to be female.

This study refutes earlier suggestions that doctors qualified outside the UK (either in South Asia, Africa, or continental Europe) are high volume prescribers of anxiolytics and hypnotics. ${ }^{1}$

The positive correlation between the prescribing volumes for anxiolytics and hypnotics, major tranquillisers, and antidepressants implies that higher prescribing of anxiolytics and hypnotics is not substituting for other psychotropic medication in these practices. Instead, higher prescribing levels of anxiolytics and hypnotics appears to occur within a context of higher overall psychotropic prescribing.

\section{Strengths and limitations of the study}

This is the first national study to explore determinants of anxiolytic and hypnotic prescribing. It is also the first study to explore the interaction between prescribing and ethnicity based on the five ethnic groupings used in the 2001 UK Census, and to link these prescribing data to QOF data.

However, several limitations may affect the interpretation of the findings. First of all the model that has emerged explains a relatively small part of the variation in anxiolytic and hypnotic prescribing.

\section{Table 3. Multivariate associations between anxiolytic and hypnotic prescribing volume and 10 predictor} variables.

\begin{tabular}{|c|c|c|}
\hline Variable & $\begin{array}{l}\text { Adjusted regression coefficient, } \\
\qquad \mathrm{B}(95 \% \mathrm{Cl})\end{array}$ & $\begin{array}{l}\text { Standardised adjusted } \\
\text { regression coefficient, } \beta\end{array}$ \\
\hline (Constant) & 22653.9 (21 096.9 to 24210.9$)$ & \\
\hline Proportion of population from a black or black British ethnic group & $-230.7(-261.7$ to -199.7$)$ & $-0.22^{\mathrm{a}}$ \\
\hline Clinical Care domain total points achieved & $-17.6(-21.0$ to -14.1$)$ & $-0.12^{\mathrm{a}}$ \\
\hline Proportion of population from an Asian or Asian British ethnic group & $-59.4(-69.9$ to -48.9$)$ & $-0.12^{\mathrm{a}}$ \\
\hline Serious mental illness unadjusted prevalence & 133908.5 (104 058.3 to 163758$)$ & $0.09^{\mathrm{a}}$ \\
\hline Proportion of female GPs & $-2018.7(-2509.8$ to -1527.7$)$ & $-0.08^{\mathrm{a}}$ \\
\hline Organisational domain total points achieved & $-23.1(-29.9$ to -16.4$)$ & $-0.08^{\mathrm{a}}$ \\
\hline Training practice & $-914.4(-1231.6$ to -597.3$)$ & $-0.06^{\mathrm{a}}$ \\
\hline Proportion of population from a mixed ethnic group & $-249(-403.5$ to -94.5$)$ & -0.05 \\
\hline Proportion of population from a Chinese or other ethic group & $-119.6(-222.6$ to -16.7$)$ & -0.03 \\
\hline
\end{tabular}

Note: This model explains $20.5 \%$ of variation. ${ }^{a}$ Significance of $\beta, P<0.001$. 
An ecological study is unable to capture all the influences on GP prescribing thresholds. ${ }^{26}$ The study was unable to link consultation data with prescribing data which meant that the study could only link the overall volume of prescribing in each practice with the overall characteristics of the registered population rather than with the actual patients who received those prescriptions. There was no information about the comorbidities, social deprivation level of these individual patients, or prescriptions for particular age cohorts. Similarly, without consultation data it was not possible to study the prescribing indication and therefore it was not possible to determine whether medication was prescribed predominantly as an anxiolytic or as a hypnotic (the prescribing of some drugs outside Chapter 4.1 of the BNF were not included which may have a similar clinical effect).

\section{Comparison with existing literature}

The findings confirmed the association between anxiolytic and hypnotic prescribing and social deprivation. ${ }^{11,15}$ Social deprivation may act as a catalyst for anxiolytic and hypnotic prescribing and might be perceived as a coping strategy for dealing with disadvantage. Moreover, the increased prevalence of chronic physical illnesses in deprived areas is likely to increase the demand for these drugs. ${ }^{15,16}$

The finding in the current study of lower prescribing volumes in areas with higher proportions of ethnic minorities is challenging to interpret. Some studies have reported lower prevalence rates of anxiety symptoms in Caribbeans and black Africans, whereas in the Asian community, prevalence studies have produced conflicting findings. ${ }^{27-31}$ Prevalence studies need to be interpreted with caution, as findings may be a function of differences in helpseeking behaviours and social beliefs about the acceptability and management of psychological illness ${ }^{29,32-35}$ or they may represent differences in the recognition of mental health problems by health professionals. ${ }^{36-37}$

Cultural beliefs may deter patients from attending, particularly where family support is seen as the most appropriate coping method (for example, in the Bangladeshi community), or may hamper detection if, for example, alternative concepts are proffered such as belief in the role of magic (for example, in the Yoruba community). ${ }^{35}$ Consultation rates for mental disorders - in particular, anxiety and depression have been reported as lower in all immigrant groups in London general practices. ${ }^{32}$ Once patients do attend their GP, there is evidence to suggest that patients coming from ethnic minorities are less likely to have mental health problems recognised, ${ }^{36}$ and this has been shown particularly for black ethnic groups. ${ }^{37}$ Lower anxiolytic prescribing has been reported in practices with more Asian names, ${ }^{3}$ while a number of studies in the US have also reported that black Americans were prescribed fewer anxiolytics and hypnotics than white Americans. ${ }^{12-14}$ Nevertheless, the current study's findings on ethnicity need to be interpreted with caution because the proportion of ethnic minorities is highly negatively skewed and the relatively few areas with a high proportion of ethnic minorities would have a disproportionate effect on the regression model.

The study provided evidence that variables describing, in broad terms, higher quality of care were associated with lower volumes of anxiolytic and hypnotic prescribing. It could be postulated that practices that achieve higher scores for Clinical Care and Organisational domains are likely to be better organised practices, functioning at a higher level of overall clinical care and that this aura of quality might affect overall tranquilliser prescribing - a 'halo effect'. These practices may, as part of their higher quality service, have better access to talking therapists and offer an alternative approach to drug treatment of mental health problems. More successful management of long-term conditions might conceivably translate into reduced anxiety levels and reduced demands for anxiolytics and hypnotics. ${ }^{38}$ Training practices also had lower levels of prescribing, which might be related to their educational ethos or to an emphasis on the importance of communication skills, which may substitute for the issuing of a prescription., ${ }^{3,39}$

A similar understanding of the dynamics of the GP consultation might explain lower prescribing levels by female GPs. Although previously reported findings lack consistency, ${ }^{15,40}$ the link of female GPs with lower prescription rates could be attributed to the traditional consideration that female GPs are more psychosocially orientated and more patient-centred than their male colleagues. ${ }^{41,42}$

Like others, ${ }^{10}$ no evidence was found in the current study linking anxiolytic and hypnotic prescribing to the country where the GP qualified. An initial association between high prescribing and place of qualification 'disappeared' when adjusted for confounding as, for example, many of the practices where non-UK trained GPs work are located in deprived areas.

\section{Implications for future research and clinical practice}

Within the context of declining levels of anxiolytic and hypnotic prescribing, the observed prescribing variations imply that clinical 'need' is not the only determinant of prescribing. For some practices, high 
prescribing volumes may be attributable to their population characteristics. For most practices, the factors linked with higher prescribing levels are less well defined. Finally, the pursuit of improved QOF performance does appear to be aligned with the desire to restrain the prescribing of anxiolytics and hypnotics.

Further research is needed to define the reasons for the $80 \%$ of variation in prescribing which remained unexplained by the study. Factors may include inappropriate long-term prescribing, an increased tendency to opt for issuing a prescription, rather than pursuing a more psychosocial therapeutic model, or misperceptions by GPs of the demand for medication by patients. Further research is also needed on the effectiveness of strategies to reduce anxiolytic and hypnotic prescribing in these high prescribing practices.

\section{Ethics committee}

Guy's Research Ethics Committee (Chairman's action, 8/2/06)

\section{Competing interests}

The authors have stated that there are none

\section{Acknowledgements}

We would like to thank, David Lloyd (Prescribing Support Unit, The NHS Information Centre for Health and Social Care, Leeds) and the Prescription Pricing Division, Newcastle, for help in obtaining and interpreting anxiolytic and hypnotic data. We also acknowledge the role of Steve Durbaba (Department of General Practice and Primary Care, King's College London) in preparing the database.

\section{Discuss this article}

Contribute and read comments about this article on the Discussion Forum: http://www.rcgp.org.uk/bjgp-discuss

\section{REFERENCES}

1. Rogers A, Pilgrim D, Brennan S, et al. Prescribing benzodiazepines in general practice: a new view of an old problem. Health (London) 2007 11(2): 181-198.

2. Holden JD, Hughes IM, Tree A. Benzodiazepine prescribing and withdrawal for 3234 patients in 15 general practices. Fam Pract 1994; 11(4): 358-362.

3. Hull SA, Cornwell J, Harvey C, et al. Prescribing rates for psychotropic medication amongst east London general practices: low rates where Asian populations are greatest. Fam Pract 2001; 18(2): 167-173.

4. Pharoah PD, Melzer D. Variation in prescribing of hypnotics, anxiolytics and antidepressants between 61 general practices. Br J Gen Pract 1995; 45(400): 595-599.

5. Gill P, Dowell A, Harris C. Effect of doctors' ethnicity and country of qualification on prescribing patterns in single handed general practices: linkage of information collected by questionnaire and from routine data. BMJ 1997; 315(7122): 1590-1594.

6. Cormack MA, Howells E. Factors linked to the prescribing of benzodiazepines by general practice principals and trainees. Fam Pract 1992; 9(4): 466-471.

7. Holm M, Olesen F. Factors affecting prescription of psychotropic drugs in general practice. Scand J Prim Health Care 1988; 6(3): 169-173.

8. Boixet M, Batlle E, Bolibar I. Benzodiazepines in primary health care: a survey of general practitioners prescribing patterns. Addiction 1996; 91(4): 549-556.

9. Mant A, Mattick RP, de Burgh S, et al. Benzodiazepine prescribing in general practice: dispelling some myths. Fam Pract 1995; 12(1):37-43.

10. Hull SA, Aquino P, Cotter S. Explaining variation in antidepressant prescribing rates in east London: a cross sectional study. Fam Pract 2005; $22(1): 37-42$

11. Gill P, Dowell A, Harris C. The effects of doctor ethnicity and country of qualification on prescribing patterns: an ecological study. J Clin Pharm and Ther 1999; 24(3): 194-199.

12. Pearson SA, Soumerai S, Mah C, et al. Racial disparities in access afte regulatory surveillance of benzodiazepines. Arch Intern Med 2006; 166(5): 572-579.

13. Swartz M, Landerman R, George LK, et al. Benzodiazepine anti-anxiety agents: prevalence and correlates of use in a southern community. Am J Public Health 1991; 81(5): 592-596.

14. Blazer D, Hybels C, Simonsick E, et al. Sedative, hypnotic, and antianxiety medication use in an aging cohort over ten years: a racial comparison. J Am Geriatr Soc 2000; 48(9): 1073-1079.

15. Ashton $\mathrm{H}$, Golding JF. Tranquillisers: prevalence, predictors and possible consequences. Data from a large United Kingdom survey. Br J Addict 1989; 84(5): 541-546.

16. Smolders M, Laurant M, van Rijswijk E, et al. The impact of comorbidity on GPs' pharmacological treatment decisions for patients with an anxiety disorder. Fam Pract 2007; 24(6): 538-546.

17. Department of Health. Investing in general practice: the new GMS contract. London: Department of Health, 2003.

18. Health and Social Care Information Centre. National Quality and Outcomes Framework statistics for England 2004/5. Statistical Bulletin 2004/05/HSCIC. 2005. http://www.icservices.nhs.uk/qofdocuments/Bulletin.PDF (accessed 11 May 2009).

19. NHS Executive. The new NHS, modern and dependable: a national framework for assessing performance. London: Department of Health, 1998.

20. Department of Health. Quality and outcomes framework. GuidanceUpdate August 2004.

http://www.dh.gov.uk/assetRoot/04/08/86/93/04088693.pdf (accessed 29 Apr 2009).

21. McKeon AJ. A guide to Personal Medical Services pilots under the NHS (Primary Care Act) 1997. London: Department of Health, 1997.

22. Majeed A, Evans N, Head P. What can PACT tell us about prescribing in general practice? BMJ 1997; 315(7121): 1515-1519.

23. Walley T, Roberts DJ. Average daily quantities: a tool for measuring prescribing volume in England. Pharmacoepidimiol Drug Saf 2000; 9(1): $55-58$.

24. Lloyd DC, Harris CM, Roberts DJ. Specific therapeutic group age-sex related prescribing units (STAR-PUs): weightings for analysing general practices' prescribing in England. BMJ 1995; 311(7011): 991-994.

25. Office of the Deputy Prime Minister. The English indices of deprivation 2004: Summary (revised). 2007.

http://www.communities.gov.uk/documents/communities/pdf/131206. pdf (accessed 11 May 2009).

26. Greenhalgh P, Gill P. Pressure to prescribe. BMJ 1997; 315(7121): 1482-1483.

27. Bhui K, Bhugra D, Goldberg D, et al. Cultural influences on the prevalence of common mental disorder, general practitioners' assessments and help-seeking among Punjabi and English people visiting their general practitioner. Psychol Med 2001; 31(5): 815-825.

28. Weich S, Nazroo J, Sproston K, et al. Common mental disorders and ethnicity in England: the EMPIRIC study. Psychol Med 2004; 34(8): 1543-1551.

29. Shaw CM, Creed F, Tomenson B, et al. Prevalence of anxiety and depressive illness and help seeking behaviour in African Caribbeans and white Europeans: two phase general population survey. BMJ 1999; 318(7179):302-306.

30. Nazroo JY. Ethnicity and mental health: findings from a national community survey. London: Policy Studies Institute, 1999.

31. Maginn S, Boardman AP, Craig TK, et al. The detection of psychologica problems by general practitioners - influence of ethnicity and other demographic variables. Soc Psychiatry Psychiatr Epidemiol 2004; 39(6): 464-471.

32. Gillam SJ, Jarman B, White P, et al. Ethnic differences in consultation rates in urban general practice. BMJ 1989; 299(6705): 953-957.

33. Neighbors HW, Caldwell C, Williams DR, et al. Race, ethnicity, and the use of services for mental disorders. Results From the National Survey of American Life. Arch Gen Psychiatry 2007; 64(4): 485-494.

34. Millet PE, Sullivan BF, Schwebel AI, et al. Black Americans' and White Americans' views of the etiology and treatment of mental health problems. Community Ment Health J 1996; 32(3): 235-242.

35. Lavender H, Khondoker AH, Jones R. Understandings of depression: an interview study of Yoruba, Bangladeshi and White British people. Fam Pract 2006; 23(6): 651-658. 
36. Bhui K, Bhugra D, Goldberg D, et al. Cultural influences on the prevalence of common mental disorder, general practitioners' assessments and help-seeking among Punjabi and English people visiting their general practitioner. Psychol Med 2001; 31(5): 815-825.

37. Commander MJ, Dharan SP, Odell SM, et al. Access to mental health care in an inner-city health district II: association with demographic factors. Br J Psychiatry 1997; 170: 317-320.

38. Das-Munshi J, Stewart R, Ismail K, et al. Diabetes, common mental disorders, and disability: findings from the UK National Psychiatric Morbidity Survey. Psychosom Med 2007; 69(6): 543-550.

39. Steinke DT, Bain DJ, MacDonald TM, et al. Practice factors that influence antibiotic prescribing in general practice in Tayside. $J$ Antimicrob Chemother 2000; 46(3): 509-512.

40. Verger P, Saliba B, Rouillon F, et al. Determinants of co-prescription of anxiolytics with antidepressants in general practice. Can J Psychiatry 2008; 53(2): 94-103

41. Roter DL, Stewart M, Putnam S, et al. Communication patterns of primary care physicians. JAMA 1997; 277(4): 350-356.

42. Hemminki E. Review of the literature on factors affecting drug prescribing. Soc Sci Med 1975; 9(2): 111-115. 